\title{
EL ESTADO CHILENO, LOS AGENTES FISCALES Y EL TEMPRANO ORDENAMIENTO ADMINISTRATIVO DEL ESPACIO ANDINO DE LA PROVINCIA DE TARAPACÁ (1880-1930)
}

\author{
THE CHILEAN STATE, GOVERNMENT AGENTS, AND THE \\ EARLY ADMINISTRATIVE ORGANIZATION OF THE ANDEAN SPACE \\ OF THE PROVINCE OF TARAPACÁ (1880-1930)
}

\author{
Luis Castro C. $^{1}$
}

\begin{abstract}
En la década de 1880, una vez afianzada la anexión territorial de Tarapacá, Chile se abocó a su ordenamiento político-administrativo. Bajo este contexto, y tomando como base registros encontrados en los archivos de la Intendencia de Tarapacá ubicados en Iquique y en Santiago, en este trabajo se sostiene que la conjunción de los intereses salitreros rentistas con los lineamientos modernizadores llevó a que, entre las décadas de 1880 y 1930, el Estado chileno tuviera un comportamiento marcadamente distante respecto a los recursos, la población y el espacio andino de Tarapacá, lo que se reflejó en una escasa presencia del aparato fiscal como en la ausencia de una política de chilenización específica.
\end{abstract}

Palabras claves: espacio andino, ordenamiento administrativo, dificultades en el ejercicio administrativo, ausencia de chilenización, aymaras.

In the decade of the 1880s, once the territorial annexation of Tarapacá had been secured, Chile addressed its political and administrative reorganization. In this context, and based on data found in the archives of the Regional Government of Tarapacá in Iquique and Santiago, this paper argues that the conjunction of the salitre exploiters' interests with the modernizing guidelines caused the Chilean State to become markedly distant between the 1880s and the 1930s, regarding the resources, population, and Andean space of Tarapacá. This resulted in a scarce presence of the official machinery in these matters, and the absence of a specific Chileanization policy. the Aymaras.

Key words: Andean space, administrative reorganization, difficulties in administrative practice, absence of Chileanization,

A partir del dominio que comenzó a ejercer el Estado chileno en el entonces departamento de Tarapacá a comienzos de la década de 1880, las autoridades de ocupación se orientaron a afianzar tres tareas básicas. Primero, desmantelar el aparato burocrático peruano que existía en la zona con el objeto de provocar un rápido cambio de administración política. Segundo, procurar la pronta normalización de la explotación salitrera. Tercero, llevar a cabo una política de modernización amparada en un espíritu misional y civilizador ${ }^{1}$.

La conjunción de los intereses salitreros con los lineamientos modernizadores llevó a que el Estado chileno diseñara con prontitud una política económica rentista salitrera, es decir, el solventar las arcas fiscales mediante el cobro de un impuesto específico a cada quintal métrico de salitre que saliera por los puertos nortinos (la revisión conceptual y empírica del "rentismo salitrero estatal" en Castro 2005:13-36). Esta definición estratégica determinó, en lo concerniente a las riquezas naturales de Tarapacá, tanto una ocupación funcional de su territorio como una utilización restringida de sus recursos. Entre el carácter exclusivamente rentista que asumió la administración estatal chilena y el salitre como el elemento proveedor de esta renta, el modelo de desarrollo económico fiscal consecuentemente tendió a integrar una porción de la geografía tarapaqueña, la pampa y la costa, y a su vez a desafectar premeditadamente las áreas que no fueran gravitantes para su modelo tributario, especialmente el espacio andino de precordillera y altiplano (Castro 1995:34-44, 1998:390-433).

\footnotetext{
1 Instituto de Historia y Ciencias Sociales, Facultad de Humanidades, Universidad de Valparaíso, Valparaíso, Chile. quismalc@yahoo.com, luis.castro@uv.cl
} 
Así, la zona andina de Tarapacá careció de una preocupación estatal equivalente al espacio salitrero de la pampa y la costa. Ningún interés fiscal concreto hubo durante este período para, por ejemplo, construir una vía que permitiera transportar de modo rentable minerales desde yacimientos cordilleranos hacia algún muelle de embarque, tampoco un oficio expedito para aprobar solicitudes de estacas mineras situadas en esta escarpada zona geográfica, y, por si fuera poco, mucho menos un propósito decidido por llevar a los alejados lugares andinos de la provincia servicios gubernativos habilitados en propiedad. De esta manera, la aplicación de la mentada política económica rentista vino a configurar, entre las décadas de 1880 y 1930 , el sustrato que finalmente determinó el comportamiento marcadamente distante del Estado chileno respecto a los recursos, el espacio y la población andina de Tarapacá. La necesidad de asegurar la obtención de la renta a partir de la producción privilegiada del salitre condujo a que el poder político central, radicado en Santiago, terminara rápidamente desestimando el potencial económico de los pisos altos de la provincia y centrara su atención exclusivamente en la depresión intermedia, zona donde se ubicaban los salares calicheros (Castro 1998:395-396). Es decir, un espacio que no aportaba salitre, esto es, ingresos vía impuestos para las arcas fiscales, perdía valor como área estratégica de consideración económica.

La preocupación del Estado chileno por los recursos andinos y la población aymara, consecuentemente, estuvo ajena a un propósito político premeditado y a un interés fundamental por lograr una asimilación cultural específica y temprana. Por el contrario, los soportes del rentismo salitrero estatal y la asociación que hizo la burocracia fiscal entre los requerimientos prioritarios por viabilizar esta carga tributaria y la pretensión modernizadora, terminaron inhibiendo la implementación de una acción chilenizadora cabal o un ejercicio de soberanía nacional extensivo. Lo que operó, entonces, fue más bien una dinámica residual en lo que cabía socialmente en la relación Estado/indígenas.

A partir de este planteamiento, el interés central de este artículo será revisar algunos tópicos inherentes a la relación que se dio entre el Estado chileno, sus agentes y las poblaciones aymaras entre las décadas de 1880 y 1930 en el contexto del temprano ordenamiento administrativo. Más que respuestas acotadas, se privilegiará comentar ciertos aspectos sociales y políticos tomando en cuenta registros que se pesquisaron sistemáticamente en los papeles del Archivo de la Intendencia de Tarapacá ubicados tanto en Iquique como en Santiago. Aunque por el tipo de documentación que se utiliza la mirada historiográfica estará preferentemente centrada en la administración estatal. También será de interés exponer parcialmente algunos aspectos atingentes a la reacción de las propias poblaciones indígenas en un escenario social que cambió vertiginosamente.

\section{El Ordenamiento Político-Administrativo y los Registros Censales}

El 31 de octubre de 1884, una vez afianzada la dominación militar, firmado el Tratado de Paz con el Perú y materializada la firma de un Pacto de Tregua con Bolivia ${ }^{2}$, el Estado de Chile creó por ley la Provincia de Tarapacá ${ }^{3}$, una decisión político-administrativa que vino, por una parte, a formalizar la posesión chilena sobre uno de los suelos salitreros más ricos del desierto de Atacama, y, por otra, validar jurídicamente algunas resoluciones de hecho que se habían tomado -incluso consignando la legislación peruana- desde el año 1880 para administrar el territorio tarapaqueño y normalizar la producción minera ${ }^{4}$.

La culminación de este vertiginoso proceso administrativo llegó con la instauración de las Subdelegaciones. El 17 de noviembre de 1884 el Departamento de Pisagua fue dividido en tres Subdelegaciones: Pisagua, Santa Catalina y Camiña, siendo la última la adscrita al espacio andino. El territorio de la Subdelegación de Camiña comprendió, a su vez, tres Distritos: Camarones, Camiña y Aroma $^{5}$, quedando bajo su circunscripción los pueblos de Chiapa, Sotoca, Illaya, Jaiña y la quebrada de Aroma ${ }^{6}$. Por su parte, el 18 de noviembre de 1884, el Departamento de Tarapacá se seccionó en diez Subdelegaciones, ocho urbanas ${ }^{7}$ y dos rurales: Pica y Tarapacá. La Subdelegación de Pica abarcó los Distritos de Pica, Canchones y Huatacondo; en tanto a la Subdelegación de Tarapacá se le asignaron los distritos de Mamiña y Tarapacá ${ }^{8}$ (Figura 1).

La división administrativa del Departamento de Tarapacá, en el transcurso de la segunda mitad de la década de 1880 , se amplió de 10 a 13 Subdelegaciones, una determinación que tuvo por exclusivo fundamento el dar cuenta del quehacer fiscal asociado al aumento poblacional en los cantones salitreros. Ninguna intención hubo por 


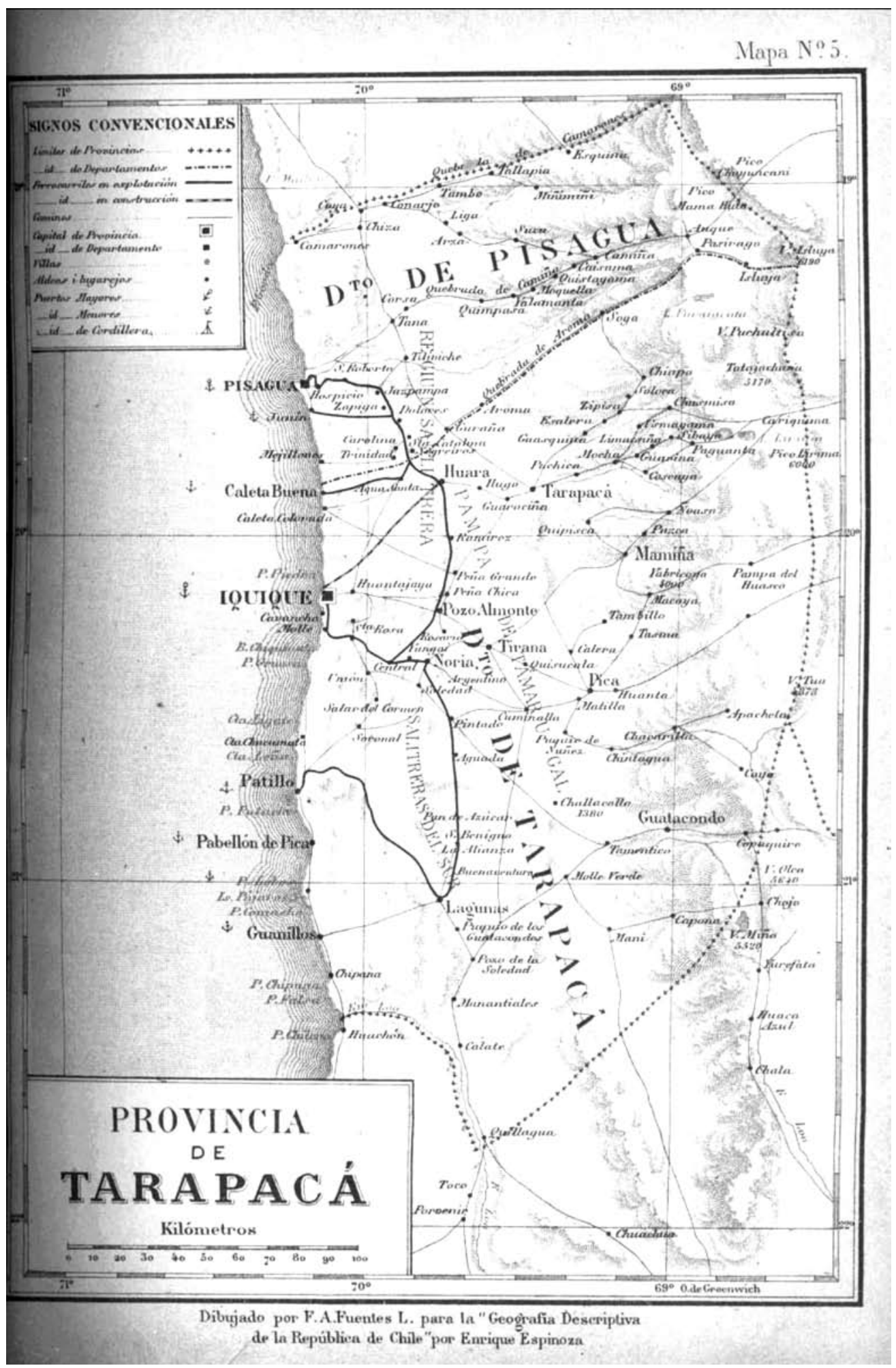

Figura 1. Mapa de la Provincia de Tarapacá 1885.

Map of the Province of Tarapacá in 1885. 
incrementar la presencia estatal en la precordillera y el altiplano'.

Junto con el ordenamiento administrativo, el Estado chileno procuró con prontitud dimensionar la población regional. Así, el 12 de mayo de 1884 el Ministerio del Interior decretó el levantamiento del primer censo chileno en Tarapacá, procedimiento que se debía llevar a cabo el 15 de junio de ese año. El censo en cuestión contemplaba registrar el nombre y los apellidos de cada habitante, sexo, edad, estado civil, profesión, capacidad de leer y escribir, lugar de nacimiento y la habilidad física y moral para vivir del trabajo personal. Además mandaba someter a verificación los datos ante una comisión de personas conocedoras de los lugares en cuestión ${ }^{10}$.

Los antecedentes que se derivaron de este ejercicio censal en lo que se refiere al espacio andino fueron variados. En abril de 1885 el Intendente Gonzalo Bulnes informó que la población rural del Departamento de Tarapacá alcanzaba a los 5.022 habitantes, de los cuales 2.695 residían en la Subdelegación de Tarapacá, 1.804 en la Subdelegación de Pica y 522 en la Subdelegación de Challacollo (Tabla 1) ${ }^{11}$. El 19 de noviembre de 1885, el encargado del Departamento de Pisagua consignaba que la distribución poblacional de las localidades interiores (Soga, Jaiña, Chiapa, Camiña, Sotoca, Cariquima, Manque, Isluga, Mullure, Miñimiñi, Nama y Camarones) equivalía a 3.610 habitantes (Tabla 2). Según su opinión, si

Tabla 1. Población rural del Departamento de Tarapacá 1885. Rural population of the Department of Tarapacá in 1885.

\begin{tabular}{clcr}
\hline Subdelegación & \multicolumn{1}{c}{ Distrito } & $\begin{array}{c}\mathrm{N}^{\circ} \\
\text { Habitantes }\end{array}$ & Totales \\
\hline \multirow{5}{*}{ Tarapacá } & Quebrada Tarapacá & 925 & \\
& Mocha & 415 & \\
& Sibaya & 393 & \\
& Cariquima & 266 & \\
& Sotoca & 139 & \\
& Mamiña & 557 & 2.695 \\
\hline \multirow{2}{*}{ Pica } & Matilla & 1.363 & \\
& Canchones & 442 & 1.805 \\
\hline \multirow{2}{*}{ Challacollo } & Cerro Gordo & 196 & \\
& Guatacondo & 326 & 522 \\
\hline Total & & & 5.022 \\
\hline
\end{tabular}

Fuente: AIT, vol. 291, sin fol. además se tomaba en cuenta a los residentes de los pueblos de Aroma, Chiza, Oscana, Tana, Corsa y otros lugares, el número de habitantes rurales del Departamento de Pisagua podía ascender a más de cinco mil personas ${ }^{12}$. En junio de 1892 el Intendente de Tarapacá informa que la población residente en la precordillera y el altiplano alcanzaba a las 13.710 habitantes, 7.031 en el Departamento de Tarapacá y 6.679 en el Departamento de Pisagua (Tabla 3$)^{13}$. Semanas más tarde, el 1 de julio, el Gobernador de Pisagua remite a la Intendencia, en cumplimiento de su informe administrativo anual, el antecedente de que la población asentada "al interior" en el Departamento a su cargo alcanzaban a los 3.125 moradores, cifra que contradice el guarismo entregado por la máxima autoridad política de la provincia (Tabla 4) ${ }^{14}$. Para 1919, un interesante informe emitido por el Visitador de Escuelas Juan Guillermo Álvarez, como parte de su Memoria Anual

Tabla 2. Población rural del Departamento de Pisagua 1885. Rural population of the Department of Pisagua in 1885

\begin{tabular}{lc}
\hline Localidad & $\mathrm{N}^{\circ}$ Habitantes \\
\hline Soga & 150 \\
Jaiña & 200 \\
Chiapa & 300 \\
Camiña & 950 \\
Sotoca & 350 \\
Cariquima & 150 \\
Manque & 50 \\
Isluga & 400 \\
Mullure & 60 \\
Miñimiñi & 150 \\
Nama & 50 \\
Camarones & 800 \\
\hline Total & 3.610 \\
\hline
\end{tabular}

Fuente: AIT, vol. 74, sin fol.

Tabla 3. Población rural de la Provincia de Tarapacá 1892. Rural population of the Department of Tarapacá in 1892.

\begin{tabular}{cccc}
\hline Departamento & Subdelegación & $\mathrm{N}^{\circ}$ Habitantes & Totales \\
\hline \multirow{4}{*}{ Tarapacá } & Tarapacá & 4.225 & \\
& Pica & 2.160 & \\
& Challacollo & 646 & 7.031 \\
\hline \multirow{3}{*}{ Pisagua } & Aroma & 4.429 & \\
& Camiña & 160 & \\
& Camarones & 2.090 & 6.679 \\
\hline Total & & & 13.710 \\
\hline
\end{tabular}

Fuente: AIT, vol. 249, sin fol. 
Tabla 4. Población rural del Departamento de Pisagua 1892. Rural population of the Department of Pisagua in 1892.

\begin{tabular}{lc}
\hline Localidad & $\mathrm{N}^{\mathrm{o}}$ Habitantes \\
\hline Camiña & 450 \\
Cinsama (sic) & 110 \\
Quistagama & 120 \\
Moquilla & 450 \\
Corsa & 35 \\
Chapiquilla & 250 \\
Soga & 155 \\
Isluga & 520 \\
Mullure & 80 \\
Miñimiñi & 230 \\
Nama & 25 \\
Camarones & 150 \\
Guacaraní & 250 \\
Esquiña & 300 \\
\hline Total & 3.125 \\
\hline
\end{tabular}

Fuente: AIT, vol. 242, sin fol.

sobre la Instrucción Primaria de la Provincia de Tarapacá, consigna que la población rural llegaba a los 10.394 habitantes (Tabla 5) (5) $^{15}$.

La preocupación por cuantificar la población regional y, entre ellas la indígena y/o rural, fue latente a lo largo de las décadas de 1890 a 1910 al interior del aparato estatal de Tarapacá, una modalidad que fue vista por las autoridades tarapaqueñas con mayor jerarquía como un efectivo instrumento de ejercicio administrativo en los territorios más alejados de la provincia. Sin embargo, la ejecución más o menos periódica de los registros censales no conllevó una modificación sustantiva y radical respecto a un posicionamiento material efectivo del aparato fiscal en la zona andina. Ni escuelas, ni oficinas de registro civil, ni notarías, ni destacamentos de policías fueron habilitados como causa de algún análisis originado a partir de los antecedentes cuantitativos que se habían recogido durante este período ${ }^{16}$. Por si fuera poco, parte importante de esta recopilación demográfica fue realizada sin una metodología adecuada y un propósito político específico. En este sentido, entender estos procedimientos como una clara evidencia de la temprana penetración chilena en el espacio andino tarapaqueño dista bastante de la realidad. Sin duda que hubo preocupación de Intendentes, Gobernadores y Subdelegados por conocer la situación demográfica de las poblaciones indígenas o rurales, pero esto poco tuvo que ver con una política de dominación socio-cultural
Tabla 5. Población rural de la Provincia de Tarapacá 1919. Rural population of the Department of Tarapacá in 1919.

\begin{tabular}{|c|c|}
\hline Localidad & $\mathrm{N}^{\circ}$ Habitantes \\
\hline Quebrada de Tarapacá & 704 \\
\hline Mocha & 150 \\
\hline Sibaya & 150 \\
\hline Sotoca & 94 \\
\hline Mamiña & 364 \\
\hline Pica & 973 \\
\hline Matilla & 299 \\
\hline Challacollo & 1.923 \\
\hline Valle de Quisma & 225 \\
\hline Cariquima & 263 \\
\hline Collahuasi & 1.422 \\
\hline Cuminalla & 53 \\
\hline Chusmiza & 95 \\
\hline Guatacondo & 251 \\
\hline Huaviña & 194 \\
\hline Huasquiña & 109 \\
\hline Laonzana & 100 \\
\hline Las Carpas & 108 \\
\hline Limagsiña & 88 \\
\hline Macaya & 117 \\
\hline Pachica & 100 \\
\hline Parca & 50 \\
\hline Sipisa & 100 \\
\hline Chiapa & 753 \\
\hline Isluga & 338 \\
\hline Soga & 126 \\
\hline Corsa & 35 \\
\hline Moquella & 126 \\
\hline Camiña & 209 \\
\hline Miñimiñi & 142 \\
\hline Cancavares & 54 \\
\hline Huancare & 83 \\
\hline Esquiña & 143 \\
\hline Jaiña & 146 \\
\hline Carmen & 40 \\
\hline Guisama & 77 \\
\hline Chapiquiña & 127 \\
\hline Pisiga & 63 \\
\hline Total & 10.394 \\
\hline
\end{tabular}

Fuente: ARTIT, vol. 6, Memorias Públicas 1918, sin fol.

explícita, sino más bien se acotó a un apéndice necesario en el ejercicio de soberanía como en lo tocante al espíritu modernizador que embargaba a quienes ejercían roles públicos en esta región. De este modo, el anexar ciertos datos censales se hizo recurrente en todo tipo de informes, especialmente para graficar lo escasa que era la presencia chilena en las zonas interiores. 
A fines del año 1927 el Ministerio del Interior, a través de la Intendencia de Tarapacá, instruyó a los Subdelegados de zonas rurales y, estos últimos a su vez a los Inspectores de Distritos, el levantamiento de un censo poblacional y económico. En esta ocasión los requerimientos fueron más específicos en comparación a los demandados en 1883. Por ejemplo, para los habitantes rurales se tenía que indagar: nombre y apellidos del jefe de familia y su mujer, constancia de estar casado, nombre y edad de los hijos y las personas que estuvieran bajo su dominio, el trabajo a que se dedicaba, si era dueño de un predio, forma como lo había adquirido, si lo arrendaba y a quién, si ocupaba el predio sin título, si lo trabajaba incondicionalmente y, por último, clase y cantidad de animales que poseía ${ }^{17}$. Las características de las preguntas de este levantamiento censal sin duda delatan un marcado interés de las autoridades locales de la época por indagar la situación legal de las tierras que ocupaban los campesinos aymaras en los distritos precordilleranos y altiplánicos. Esto no debe extrañar porque en el transcurso de las décadas de 1910 a 1920 este tema -el uso de las tierras fiscales- fue fruto de una nutrida discusión en el ámbito de proyectos de desarrollo regional (Castro 2005). Por tanto, la idea de ejecutar un censo dirigido puntualmente al quehacer económico de los aymaras rurales bien puede entenderse como una de las primeras muestras de un cambio en la gestión fiscal, una inflexión que comenzaba a visibilizar a los indígenas y hacer patente la necesidad de instaurar una presencia fiscal más consistente y continua, un ejercicio que hasta ese momento el Estado chileno sólo había realizado parcialmente.

\section{Las Dificultades en el Ejercicio Administrativo}

El ordenamiento administrativo del espacio andino de la provincia de Tarapacá establecido en el año 1884 rápidamente encontró dificultades en su implementación. No sólo la ausencia de chilenos para ocupar los cargos de Subdelegado, Inspectores y Jueces de Subdelegación y Distrito caracterizó este proceso, sino también los obstáculos de movilidad y carencia de infraestructura para ejercer en propiedad los roles fiscales.

Muy tempranamente, el 14 de julio de 1885, los vecinos de Camiña reclamaban por los abusos cometidos por el Subdelegado Francisco Palla
Loayza y el Juez Juan de la Cruz Pizarro. A entender de estos vecinos, esta situación era inconcebible tomando en cuenta que estas autoridades eran naturales de la localidad y además representantes de un mandato legal que les impedía involucrarse en pugnas personales y privadas aprovechándose de sus cargos:

Los que suscriben vecinos del pueblo de Camiña a VS. respetuosamente exponemos que la actitud que, de algunos meses a esta parte, han asumido respecto de nosotros las autoridades de esta localidad, nos obligan, muy a pesar nuestro, a distraer la atención de VS. con el objeto de que se sirva dictar una providencia que ponga término a los abusos de que venimos siendo víctimas. (...) Parecerá extraño, señor Intendente, que personas nacidas en el mismo pueblo, que deberían mirar con benevolencia y respeto a los que ayer nomás eran sus compatriotas, hagan uso de la tiranía que, por lo mismo que es ejercida por autoridades inmediatas y subalternas, es más opresiva e intolerable. Larga sería la enumeración de los abusos cometidos por el subdelegado en el desempeño de su puesto que más para otra cosa le sirve para ejercitar venganzas personales por antiguos rencores de familia, y disensiones locales, y para convertir en chacras productivas las incultas heredades que posee ${ }^{18}$.

Esta denuncia es bastante sintomática de algunos aspectos que persistieron en las décadas de 1880 a 1920 en lo que se refiere a la relación Estado/ indígenas-campesinos. Uno, delata el poco interés de los chilenos residentes en Tarapacá por ocupar cargos públicos en las áreas rurales, caso que adquiere mayor notoriedad si se toma en cuenta que el pueblo de Camiña era bastante accesible desde la pampa salitrera y por tanto no debía representar mayores dificultades para el ejercicio administrativo por parte de agentes nacionales. Dos, la mínima complicación por parte de la administración estatal por designar a peruanos en este tipo de oficios públicos (y no digo explícitamente aymaras porque para el fisco chileno esta categoría no tenía existencia jurídica en tanto ciudadanos, como tampoco reconocimiento político y social). Tres, lo interesante que resulta el reclamo en cuestión desde la perspectiva de que en 
ningún momento en él se consignó como origen de los inconvenientes la presencia del aparato estatal chileno sino, por el contrario, como una acción de individuos, uno de ellos derechamente indígena, que se habían aprovechado de una posición privilegiada para resolver malamente diferencias personales.

Este último aspecto es reafirmado a mediados de 1889 cuando 35 destacados vecinos residentes del pueblo de Tarapacá elevaron una sentida solicitud al Intendente Ramón Yávar para que mantuviera en su cargo al Subdelegado chileno Manuel Segundo Muñoz, una petición que estuvo graficada por la ascendencia peruana de los firmantes y el supuesto valer personal del mencionado funcionario fiscal:

Los que suscriben, naturales y vecinos de Tarapacá, y por consiguiente de nacionalidad peruana, a US. presentándonos, con todo respecto, por el digno órgano de nuestro Cónsul General que reside en Iquique, decimos: que habiendo llegado a nuestro conocimiento que US. trata de cambiar con otra persona al actual subdelegado interino de esta localidad don Manuel Segundo Muñoz B. y teniendo presente que este hecho nos es bastante sensible por cuanto la amabilidad, buenas maneras y demás cualidades personales del señor Muñoz B. lo hace acreedor a nuestra humilde estimación y aprecio, hemos acordado molestar las altas atenciones de US. para suplicarle, como lo hacemos, revoque el pensamiento del cambio a que nos referimos y antes, si quiere, expedir el respectivo título en propiedad para que el señor Muñoz continúe en el puesto de subdelegado que con tanto acierto y tino ha desempeñado hasta el presente con aplauso general de todos los habitantes de la Subdelegación ${ }^{19}$.

La predominancia de las interacciones personales por sobre las institucionales, en lo que tocaba al ejercicio de los agentes administrativos chilenos en el espacio andino, caracterizará buena parte de las primeras décadas de la presencia chilena en Tarapacá. Desde este punto de vista, los cargos como los conflictos existentes entre ciertos lugareños de los pueblos vallesteros, precordilleranos y altiplánicos con Inspectores y Jueces de Distrito y Subdelegación darán cuenta reiteradamente de esta situación, un aspecto que se profundizará en la medida que los residentes litigantes fueran chilenos y las autoridades fiscales de origen peruano-indígenas. Tal fue el caso de la queja que hizo José del Carmen Guerrero contra el Inspector de Sotoca en 1893. De acuerdo a las pesquisas del Subdelegado Robledo, este requerimiento tuvo por propósito detener la fiscalización que llevaba a cabo en ese momento el mencionado Inspector sobre los reiterados abusos que Guerrero y su hijo habían cometido contra los indígenas del lugar:

Nadie me ha hecho una queja en su contra, y por el contrario las personas con quién tuve oportunidad de hablar al respecto me manifestaron encontrarse muy satisfechas con su proceder como autoridad. Con respecto a la queja de Don José del Carmen Guerrero ella no es la más imparcial ni la más digna de fe porque dicho señor acompañado de su hijo cuando se embriagan, y esto lo hacen con frecuencia, se entregan a toda clase de actos censurables abusando con los pobres indígenas quienes le tienen un miedo pánico; con este motivo ha habido varias quejas en contra de ellos ante el Inspector ${ }^{20}$.

El carácter personalista que adquirió el ejercicio administrativo chileno en la zona andina de valles y precordillera, como los obstáculos de desplazamiento y carencia de medios fiscales, se acentuaron aún más a medida que se ascendía en dirección a la cordillera, siendo la lejanía un factor de primer orden para la escasa -y en algunos casos ninguna- presencia del aparato estatal chileno en el altiplano. Precisamente esto delata el Subdelegado de Tarapacá Evaristo Sanz al informar, el 25 de mayo de 1895, que la posibilidad que él tenía de verificar el incidente protagonizado por el Inspector de Cariquima referente a la violación que había hecho de la frontera boliviana acompañado de una grupo de lugareños para recuperar animales robados se limitaba en efectividad por:

...la distancia de más de treinta leguas que nos separa de la línea [fronteriza]; como también por la carencia absoluta de guarnición de caballería en que se han mantenido hasta la fecha [los Distritos], en que si es verdad que hoy tenemos dos soldados de policía de a pie da por resultado que sus 
servicios son completamente inútil en un pueblo como este que por lo general es tranquilo, pero no sucede lo mismo con los cinco distritos que se encuentran a largas distancias ${ }^{21}$.

Por cierto el Inspector de Cariquima era un aymara altiplánico que, en lo tocante al cruce de la frontera para recuperar los animales sacados supuestamente de su comunidad, actuó al amparo de parámetros locales que tenían que ver con diferencias y rivalidades con grupos indígenas bolivianos más que con un criterio propio de un agente chileno al amparo de una directriz política estatal. En este sentido, el Subdelegado de Tarapacá fue muy sagaz en su informe denotando claramente este aspecto, a pesar de su carga discriminatoria, al referirse a los hechos:

Sobre la reclamación que hace el corregidor boliviano de Llica en su nota del 22 de abril pasado la encuentro hasta cierto punto justa, pues el infrascrito tenía ya conocimientos que el Inspector de Cariquima con una partida de indios traspasó la línea en busca de reparaciones [recuperación] de animales perdidos, $\mathrm{y}$ habiéndosele insolentado uno de los indios bolivianos lo hizo amarrar a un árbol. Por lo expuesto verá SS. que los ánimos de una y otra indiada se encuentran muy agravados y que no será muy difícil, atendiendo el carácter fuerte y poca civilización, se vayan a las manos el día menos pensado sucediendo algunas desgracias que pudieran traer por consecuencia reclamaciones en contra de esta Subdelegación por no haber tomado medidas en tiempo de los reclamos de ambas tribus ${ }^{22}$.

La falta de chilenos para ocupar los cargos públicos, de este modo, pasó a ser parte de los rasgos constitutivos de la presencia estatal en la zona andina de Tarapacá, haciendo que los Subdelegados tuvieran que lidiar no pocas veces con este inconveniente tratando de solucionar como pudieran la falta de autoridades fiscales. Esta falencia se vio acentuada tanto por la escasa atención que le prestó el gobierno central a este problema al estar más preocupado de los vaivenes salitreros, como por la existencia de una visión discriminadora que hizo a muchos agentes fiscales asumir la postura de que era inconducente el ejercicio civilizador del Estado en lugares con una población mayoritariamente indígena. El Intendente Gonzalo Bulnes, en un oficio emitido el 5 de junio de 1884, graficó nítidamente este dilema al explicitar su pensamiento de cómo se debía administrar políticamente la provincia tarapaqueña:

El servicio administrativo o judicial no puede ser concejil en este territorio, sino en determinados lugares. Puede serlo en las poblaciones de la costa, a donde sería fácil hallar hombres de competencia y de buena voluntad que desempeñaran el cargo y sería difícil encontrarlos en la región salitrera e imposible en el interior porque tal vez en todas las quebradas no vive un solo chileno. (El subrayado es mío) ${ }^{23}$.

Esta inquietud de la máxima autoridad política de Tarapacá quedará corroborada con la nota que el Subdelegado de Tarapacá, A. Robledo, le envió el 30 de agosto de 1893 informándole sobre la escasez de Jueces de Distrito:

Cumplo con el deber de participar a US. que por más que he buscado en Mocha, Sibaya y Sotoca quienes pudieran ser nombrados Jueces de Distritos respectivamente, no he encontrado. Ninguno de los pobladores, de los que pudieran desempeñar dichos puestos, quieren aceptarlo; se niegan y apelan a su condición de peruanos para que por fuerza no se les obliguen a servir.

Lo expuesto no le parezca extraño a VS. pues no existiendo en toda la Subdelegación más chilenos que el que suscribe, el Oficial del Registro Civil, el Juez de Subdelegación y dos o tres más que residen en Tarapacá, no es raro que la administración judicial carezca del concurso de los Jueces de Distrito por falta como he dicho antes de personas quienes quieran aceptar el cargo ${ }^{24}$.

Diecisiete años más tarde las dificultades a las que se vio enfrentado el Subdelegado Robledo seguían subsistiendo. El 12 de enero de 1911 el Subdelegado de Tarapacá, Mauricio Reynaud, procedió a informar al Intendente Carlos Vargas Clark que en vista de las reiteradas quejas de los habitantes de Cariquima en contra de José Mamani 
en su calidad de Inspector de Distrito, lo había suspendido de su puesto reemplazándolo por Esteban Challapa, es decir un aymara por otro aymara, o mejor dicho desde la perspectiva del Estado chileno de aquella época, un peruano por otro peruano ${ }^{25}$. Por si fuera poco, al mes siguiente Reynaud notifica que la acefalía del puesto de Juez de Subdelegación estaba provocando innumerables reclamos de los residentes de su jurisdicción que demandan una presencia más efectiva de la administración estatal chilena ${ }^{26}$.

Así, la falta temporal de autoridades estuvo lejos de ser una situación aislada hacia las primeras décadas del siglo XX, y no fueron pocas las veces que algunos residentes de estas localidades se quejaron por aquello. Por ejemplo, el 16 de marzo de 1917 el cura y vicario de Mamiña Juan Brus le planteó a la máxima autoridad de la provincia que:

Hace más de ocho meses que este pueblo de Mamiña está sin ninguna autoridad. Hace meses se nombró a don Esteban Bacian de Juez, pero hasta la fecha no se hizo cargo de su puesto, está trabajando en las oficinas [salitreras] y no piensa venirse, ni habrá renunciado ${ }^{27}$.

Junto con la falta reiterada de ciertos agentes fiscales como de individuos chilenos para ocupar cargos administrativos, también representó una situación rutinaria no resuelta por las instancias estatales correspondientes las deficiencias recurrentes derivadas por la ubicación residencial inapropiada de algunos de estos burócratas, muchos de los cuales prefirieron vivir en pueblos alejados del espacio que debían conducir políticamente pero cercanos a la pampa salitrera. En este último aspecto tenemos el caso del Subdelegado de Tarapacá, Pablo Kimpoe, que a fines de 1912 llegó a ser oficiado por el propio secretario del Intendente, C. Rodríguez, para que cambiara su lugar de residencia:

El señor Intendente me encarga decir a Ud. que continuamente está recibiendo quejas respecto a lo apartado del lugar en que tiene Ud. su residencia [Huarasiña], lo que impide que Ud. pueda imponerse de las necesidades de los demás pueblos de su Subdelegación. El Juez de Subdelegación de Tarapacá se queja también de esto mismo y dice que le es muy difícil se le facilite policías para llevar a efecto algunas diligencias judiciales, y cuando llega[n] a [los lugares] no llega[n] en la debida oportunidad. Por este motivo el Sr. Intendente me dice se sirva manifestarle si podría fijar su residencia en algunos de los pueblos de Mocha o Tarapacá que son de más población e importancia a fin de evitar nuevos retrasos ${ }^{28}$.

Esta deficitaria presencia estatal provocó que la esperada acción chilenizadora fuera nada más que una aspiración personal de algunos agentes fiscales, muchos de los cuales no podían entender la falta de preocupación por parte del aparato central del Estado en un tema que, según sus pareceres, tenía vital importancia en el ejercicio de la soberanía política, territorial y social. Mirado desde este punto de vista, cierta chilenización compulsiva de las poblaciones indígenas y campesinas de Tarapacá no pasó de ser una cuestión muy focal asumida exclusivamente por algunos grupos o individuos xenofóbicos, como el Inspector de Huaviña, un chileno de apellido González, que el 5 de mayo de 1918 denunció la práctica por parte de los residentes de este pueblo de tradiciones aperuanadas, acciones que según su opinión eran protegidas indebidamente por Francisco Jachura en su calidad de Juez de distrito:

Por el presente me tomo el atrevimiento de dirigirme a VS. para informarle la mancha del pueblo de que soy Inspector y fiel súbdito de VS., el pueblo de Huaviña con 280 vecinos, costumbres antiguas casi todos quieren conservar las costumbres del Perú y no las leyes chilenas por lo que el que suscribe pasa grandes sofocones; en este pueblo hay un Juez de distrito pero es aperuanado y pongo en conocimiento de VS. como ejerce su cargo ${ }^{29}$.

Inesperadamente, para los conceptos que manejaba González de lo que debía ser el resguardo de la chilenidad en estos territorios díscolamente peruanos, Jachura fue resueltamente defendido por el Subdelegado Valdivia, quien no escatimó en señalarle al Intendente de que:

El Juez de distrito don Francisco Jachura, hijo de ese pueblo, es una persona de buenos antecedentes y de posesión holgada y que si bien no tiene la suficiente preparación 
para desempeñar correctamente el cargo, le abonan sus buenos y correctos procedimientos de hombre honrado. Debo hacer presente a VS. que en estos pueblos no se encuentran personas aptas para desempeñar debidamente los cargos de jueces de distritos e inspectores, y el Subdelegado cada vez que ha tenido que hacer alguno de estos nombramientos se ha informado de los vecinos [que] podrían desempeñar con más acierto. El único pueblo de esta Subdelegación donde se nota este malestar es en el de Huaviña que son más bien rencillas del Inspector González con el juez de distrito por cuestiones, que al ser verdad, en nada favorecen a dicho Inspector ${ }^{30}$.

Si bien por más de cincuenta años la presencia de residentes peruanos y/o indígenas en algunas de las funciones de administración no fue un dilema para el Estado chileno, como tampoco el requerir una afanosa chilenización de estos lugares, la crisis desatada a fines de la década de 1920 del modelo rentista amparado en la explotación salitrera provocó un cambio relevante en la mirada estratégica del aparato fiscal. En este ámbito, el 8 de octubre de 1927 el Subdelegado de Camiña, Pedro Guerrero, resumirá nítidamente esta perspectiva al comunicarle al Intendente Daniel Espejo de que:

salvo mejor acuerdo de US. me propongo exigir de los Inspectores dedicación al cargo, moralidad, rectitud, buenas costumbres y acatamiento a las instrucciones del Subdelegado, a fin de prestigiar la administración chilena que parece no haber existido o dejado muy poca huella (El subrayado es mío) ${ }^{31}$.

En adelante, el interés por recuperar terreno será una tarea primordial para el Estado chileno, un propósito que se llevará a cabo mediante la escuela pública (Castro 2004) y la penetración efectiva de las oficinas estatales mediante ciertas políticas de asistencialidad (González 2002; Gundermann 1997).

\section{Los Agentes Fiscales, su Visión del Espacio Andino y de los Aymaras}

Es sintomático que en el transcurso de las décadas de 1880 a 1930 no hubo una categorización fiscal específica sobre los aymaras, predominando en este ámbito la adscripción a la nacionalidad peruana en lo que tenía relación con lo político. Dado que desde el punto de vista legal los indígenas como las comunidades no tenían existencia, la percepción de los burócratas estatales chilenos sobre estas poblaciones estuvo marcada por connotaciones sociales diversas. El uso de categorías como peruanos, indios, indiada, indígenas, naturales, lugareños, agricultores y campesinos se hizo recurrente, denotando la reproducción de percepciones variables que poco tuvieron que ver con un modelo exprofeso de chilenización, sino más bien con el establecimiento de una relación entre el lugar de residencia y el mayor o menor grado de adscripción a los parámetros culturales que se entendían como parte de una sociedad civilizada. De este modo, fue recurrente que a los habitantes de valles bajos normalmente se les tipificara como peruanos o campesinos (bajo la idea de que eran individuos "más civilizados" por estar cercanos a la pampa-costa) y a los asentados en la sierra alta y el altiplano se los identificara como indígenas o indiada (es decir, los bárbaros que vivían en lo más profundo de la cordillera) $)^{32}$.

Como se puede constatar, junto con esta diversidad de denominaciones operó una visión más o menos genérica de poblaciones atrasadas, pobres y poco civilizadas; un aspecto que delató con excepcional claridad, a mediados de 1884 , el Intendente Gonzalo Bulnes en un informe dirigido al Ministro del Interior de la época:

En estos lugares vive amontonada una población indígena, importante como número, si bien desprovisto de actividad y de energía moral. (...) Llamo especialmente la atención de VS. sobre la circunstancia de que en esa región todos sus habitantes son peruanos, sin mezcla alguna de otra nacionalidad.

En las salitreras y en las poblaciones de la costa, donde existe una activa competencia de trabajo, el elemento chileno y el extranjero, más rigorosos como fuerza y capital, han dominado por decirlo así, bajo su acción a los peruanos y puede por consiguiente mirárseles bajo el mismo punto de vista que a los demás habitantes del territorio nacional. No sucede lo mismo en las quebradas del interior. Allí 
palpita bajo la influencia de costumbres seculares, una nacionalidad distinta que conserva sus usos y su sistema de vida, su traje, su idioma y su religión, porque aún esta misma se distingue por sus prácticas infantiles, de lo que ella representa en las poblaciones civilizadas de Chile. (Los subrayados son míos) ${ }^{33}$.

La impresión, nada benevolente, que embargó al Intendente Bulnes con relación a los rasgos culturales de los aymaras fue un elemento analítico que ayudó al escaso interés que, en las décadas siguientes, demostró el Estado chileno por asentar su administración en las zonas interiores de Tarapacá, una determinación que se afianzó aún más con el enfoque rentista salitrero estatal. Desde esta perspectiva, la posición de Gonzalo Bulnes marcó rumbo en lo tocante a los lineamientos estratégicos referidos a la organización política, especialmente a la hora de justificar la posición de no hacer un mayor esfuerzo para llevar al territorio interior la administración estatal. A su entender era conveniente, en esta materia, tomar en cuenta las siguientes dificultades:

La primera cuestión que surge cuando se trata de la organización de este territorio es saber si conviene crear para aquellos lugares una sección administrativa especial. Debo dar a VS. las razones que me inclinan a contestar en sentido negativo a la pregunta anterior. Un gobernador tropezaría en el servicio administrativo con las siguientes dificultades: $1^{\circ}$ La distancia que divide las quebradas entre sí, de tal modo que siempre sería más difícil la comunicación entre una quebrada cualquiera y la capital del departamento, que entre aquella y la costa. (...) En cualquier punto que se situare un gobernador, su acción administrativa sería anulada por la distancia, y se impondría mayor molestia a sus habitantes, obligándolos a viajar a la gobernación que yendo a la pampa salitrera donde encuentran comercio, poblaciones que son su mercado de expendio y de consumo, ferrocarril para la costa, etc. $2^{\circ}$ Las quebradas del interior se encuentran en un estado de suma pobreza sin que pueda suponerse que su situación se modifique o mejore. Su agricultura es muy reducida y en cambio la población que las habita demasiado numerosa, lo que hace que el terreno por rico que sea apenas basta para la satisfacción de las más urgentes necesidades de la vida. (...) $3^{\circ}$ El peligro que bajo el punto de vista de la asimilación de la raza peruana podría traer la adaptación de un régimen administrativo severo y nuevo que viniera a trastornar sus prácticas $^{34}$.

Para Bulnes estas dificultades estructurales ameritaban una administración fiscal centripetada hacia las zonas bajas, por tanto propuso una división en dos departamentos: el de Iquique y el de Pisagua, ordenamiento que justificó arguyendo razones tales como:

hoy la región salitrera ha relegado a una escala subalterna la importancia del interior, y de aquí proviene que sus intereses administrativos deben estar subordinados a los de la costa. (...)

en pocos años más será preciso crear el departamento de Patillos, y entonces cada una de las divisiones administrativas tendrán entre sus dependencias una o dos de las quebradas más importantes del interior. Y si la raza peruana que está obligada por sus negocios a vivir en contacto con la región de la costa, se incorporaría mejor en las prácticas de nuestro sistema de gobierno y de nuestro adelanto social ${ }^{35}$.

Sin duda este tipo de planteamiento modernizador apuntó a establecer una vinculación subordinada en lo político-administrativo de la población peruana e indígena de la región, un aspecto que fue concordante con la misión civilizadora que se había impuesto Chile para con estos territorios anexados.

En estos términos, la visión de estar frente a poblaciones carentes de civilización llevó a los agentes fiscales a tener una conducta protectora de los campesinos indígenas, especialmente para frenar algunas arremetidas que intentaron ocupar sus recursos hídricos y algunas de sus tierras agrícolas y ganaderas. En este comportamiento no hubo contradicción, sino que un estricto apego a un criterio político muy refinado que buscó afianzar dos objetivos: (1) no incurrir en conflictos innecesarios con una población no chilenizada; (2) dejar 
establecido que se estaba ante una administración sometida al imperio de la ley y no a determinaciones irracionales. Precisamente esto pretendió Gonzalo Bulnes cuando le recomendó, a mediados de 1884, al Ministro de Hacienda no acceder a una concesión de exclusividad solicitada por el empresario Claudio Mackenna para ocupar los pastizales aledaños a las lagunas de Caposa, Lirima y Huasco atendiendo al hecho de que:

por un derecho secular de posesión pertenecen a reducciones de indios que viven en ellas; o que apacentan en ellas sus ganados, y que satisfacen en la escala miserable de su condición las necesidades de su vida. Conceder los pastos en absoluto como se pretende [ya que] equivaldría a obligar a poblaciones indígenas o a perecer de hambre o a migrar. En mi concepto debe darse al solicitante el libre uso de los pastos, siempre que no haya sobre ellos derechos adquiridos, de propiedad de posesión, o de costumbre ${ }^{36}$.

Este mismo criterio usó para denegar la petición a perpetuidad de las aguas de la laguna de Lirima, aduciendo que era necesario resolver si "la merced iba a ofender los derechos seculares de los habitantes de Tarapacá, o de otros puntos" 37 .

Congruente con su postura, Gonzalo Bulnes por esta misma fecha instruyó al Subdelegado de Pica que en lo tocante a "cuestiones de agua que se susciten en el lugar, es preferible para no producir una alteración violenta, sujetarse mientras tanto a las prácticas establecidas desde el tiempo de la dominación peruana" 38 .

En las décadas siguientes estos criterios de validar posesiones de hecho o seculares siguieron apareciendo como parte de las gestiones administrativas de los funcionarios estatales tarapaqueños. Por ejemplo, en 1918 la Dirección General de Obras Públicas aconsejó, analizando las fuentes hídricas posibles de utilizar en la implementación del proyecto fiscal de agua potable para Pisagua, tomar en cuenta los derechos consuetudinarios que tenía Eulogio Guacucano a las existencias acuícolas de Quiuña Bajo, privilegios que no tenían un respaldo legal ${ }^{39}$.

A medida que el tema plebiscitario se hizo más patente en el transcurso de la década 1920, la preocupación por una posible conducta altamente peruanizada por parte de la población rural e indígena adquirió mayor preponderancia. En este ámbito se conjugó, tal como lo explicitó el Subdelegado de Tarapacá A. Valdivia en un informe emitido el 28 de septiembre de 1920 sobre los residentes peruanos del valle de Tarapacá, cierta desvalorización social de estos residentes rurales, el interés por chilenizarlos efectivamente y la necesidad de modernizarlos:

salvo muy raras excepciones, los peruanos que aquí existen son pequeños propietarios de terrenos agrícolas que se dedican a esta labor y cuya cultura intelectual es tan escasa como su situación económica, que bien se les puede eliminar de inspirar sospechas de espionaje o de ser hostiles a la nación de otra forma ${ }^{40}$.

Coincidente con esta percepción, a fines de 1920 el Intendente Arturo Oyarzún Lorca no dudó en apelar ante el Ministro del Interior para que el Estado, asumiendo la precariedad cultural y de iniciativa de estos campesinos, los instruyera en las técnicas de la agricultura moderna:

En las quebradas al interior de la provincia también se producen verduras pero en escasísima proporción debido a las siguientes causas: los terratenientes del interior, gentes rústicas, sin ilustración, cultivan sus campos en la forma rudimentaria, como lo hacían sus antepasados, forma que ha venido transmitiéndose de generación en generación. Sólo producen lo necesario para vivir, pues no tienen mayores aspiraciones. (...) La labor consistiría en educar a los pequeños agricultores dentro de las normas de la agricultura moderna, familiarizarlos con los procedimientos de cultivo intensivo, de hacerlos despojarse de los rancios procedimientos que están empleando en el cultivo de sus tierras, en una palabra, vulgarizar los conocimientos agrícolas hasta hoy ignorados en esas quebradas ${ }^{41}$.

Estas expresiones de la máxima autoridad política de la provincia tuvieron directa relación con los grandes temas que se discutían por aquel entonces respecto al desarrollo de la región. Entre ellos, la posibilidad de habilitar una actividad agrícola a gran escala en la pampa del Tamarugal (Castro 2005:63-91). En este caso particular, el Intendente Oyarzún consideró un elemento que no había sido 
tomado en cuenta por quienes estaban en el meollo de estos planteamientos regionalistas: la agricultura de los valles ejecutada mayoritariamente por campesinos aymaras y su modernización a través de una injerencia estatal directa. Esto último, por cierto, consignó un perfil chilenizador no compulsivo del contingente poblacional indígena. La confirmación de este sesgo administrativo lo tenemos cuando, ante la denuncia del Subdelegado de Tarapacá oficiada el 5 de mayo de 1927 de que las fiestas religiosas de su jurisdicción eran "...verdaderos pretextos para mantener o despertar, en especial en los niños, sentimientos de adhesión al Perú y de encubierta hostilidad para Chile", la Intendencia lo único que hizo fue ordenar a Carabineros que prohibiera la venta de alcohol ${ }^{42}$, una medida que calzaba perfectamente con el espíritu civilizador que embargó recurrentemente a los funcionarios públicos.

\section{Conclusiones}

Es dable aceptar que los intereses rentistas salitreros, que centripetaron la economía regional hacia la pampa y la costa, conllevaron una escasa presencia estatal en la zona andina, sobre todo de precordillera y altiplano, en el transcurso de los primeros cincuenta años de administración chilena de la provincia de Tarapacá. Esta realidad reafirmó la ausencia de una política de chilenización para las poblaciones indígenas del interior. De hecho, para algunos funcionarios, como el Intendente Gonzalo Bulnes, la carencia moral y social de los indígenas reafirmaba la decisión de no malgastar los recursos del erario con el objeto de llevar a esos lugares la administración y la civilización.

El resultado de este desinterés permitió, en la práctica, la participación de algunos de estos aymaras en cargos públicos tales como Jueces e Inspectores de Distritos y de Subdelegación, sin embargo aquello no significó integración, sino más bien un particular modelo de asimetría política solventado, en algunos casos, mediante la aceptación por parte de estos individuos de la nacionalidad chilena o, en otros, porque no había chilenos sino sólo residentes indígenas de nacionalidad peruana disponibles para designar en estas funciones.

En este contexto analítico, es menester consignar que el Estado chileno operó en la provincia de Tarapacá lejos de un lineamiento administrativo homogéneo. Es más, en gran parte del territorio tarapaqueño fue bastante carente, lo que derivó en una predominancia de las acciones individuales de los funcionarios públicos, incluso en aquello de soberanía y chilenización, por sobre las determinaciones institucionales, cuestión que le permitió a parte de la población indígena actuar y movilizarse con cierta facilidad.

Agradecimientos: A los evaluadores y correctores de estilos que con sus observaciones y comentarios contribuyeron al resultado final de este trabajo. La actualización y finalización de este artículo se llevó a cabo en el marco del Proyecto Fondecyt $\mathrm{N}^{\circ}$ 1071014. La investigación inicial, en tanto, se desarrolló como parte del Proyecto Dipuv 02/2004. El autor es candidato a Doctor en Historia, mención Etnohistoria, Universidad de Chile.

\section{Referencias Citadas}

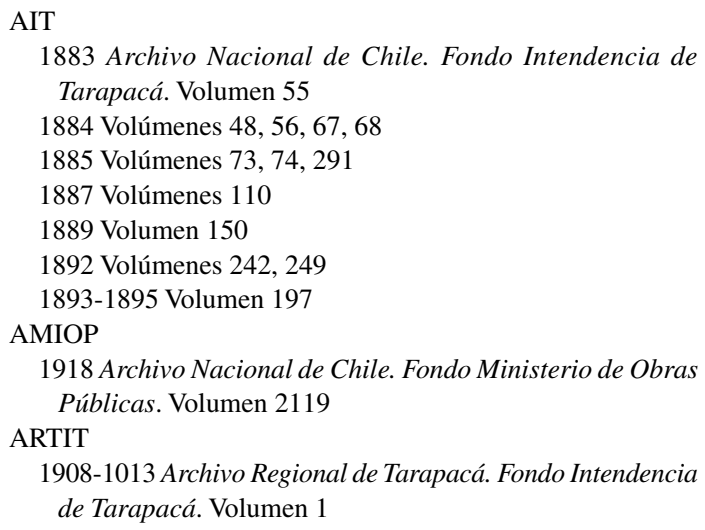

1910 Volumen 7

1911 Volumen 47

1917 Volumen 1

1918 Volúmenes 6, 16

1921 Volumen 28

1927-1928 Volumen 2

1930 Volumen 6

Álvarez, J.G.

1919 Memoria Instrucción Primaria de Tarapacá 1918. Imprenta La Nacional, Iquique.

Balmaceda, J.M.

1881 La misión civilizadora de Chile. Circular del Ministerio de Relaciones Exteriores. Diario Oficial, Santiago 25 de julio. 


\section{Castro, L.}

1995 Tarapacá 1880-1936: Debates, reflexiones, propuestas y proyectos en torno al problema del desarrollo. Temas Regionales 2(1): 32-66.

1998 Cuando el Susurro del Agua se Acalló en el Desierto: La Expropiación de las Aguas del Valle de Quisma, el Abastecimiento Fiscal a Iquique y el Debate sobre el Problema del Desarrollo Económico Regional, Tarapacá 1912-1937. Tesis Magíster en Historia, Universidad de Santiago.

2004 Una escuela fiscal ausente, una chilenización inexistente: La precaria escolaridad de los aymaras de Tarapacá durante el ciclo de expansión del salitre (1880-1920). Cuadernos Interculturales 2(3):57-68.

2005 Regionalismo y Desarrollo Regional: Debate Público, Proyectos Económicos y Actores Locales (Tarapacá 18801930). Coedición CEIP Ediciones, Universidad de Valparaíso y Universidad Santo Tomás, Viña del Mar.
González, S.

2002 Chilenizando a Tunupa. La Escuela Pública en el Tarapacá Andino 1880-1990. Coedición DIBAM, Universidad Arturo Prat, Instituto de Estudios Andinos Isluga, Centro de Investigaciones Diego Barros Arana, Santiago.

Gundermann, $\mathrm{H}$.

1997 Etnicidad, identidad étnica y ciudadanía en los países andinos y el Norte de Chile. Los términos de la discusión y algunas hipótesis de investigación. Estudios Atacameños 13: 9-26.

Pinto Vallejos, J.

1985 La sociedad tarapaqueña durante los primeros años de la ocupación chilena, 1879-1884. Nueva Historia IV (1516).

Villalobos, S., O. Silva, F. Silva y P. Estellé

1976 Historia de Chile. Vol. 4. Editorial Universitaria, Santiago.

\section{Notas}

1 Los objetivos de las primeras autoridades chilenas de Tarapacá están extensamente descritos en Pinto Vallejos (1985:107-127). La oficialización del propósito civilizador se encuentra en José Manuel Balmaceda, La misión civilizadora de Chile. Circular del Ministro de Relaciones Exteriores, Diario Oficial, Santiago 25/7/1881.

2 El Tratado de Paz con el Perú se firmó en la ciudad de Lima el 20/10/1883 y contempló la aprobación tácita por parte del Perú de que la provincia de Tarapacá se sujetara plena y perpetuamente al régimen político y administrativo de la ley chilena. En tanto el Pacto de Tregua con Bolivia se ejecutó en el mes de abril de 1884 (Villalobos et al. 1976:591).

3 AIT, vol. 48, Oficio del Jefe Político, Gonzalo Bulnes, comunicando creación y límites de la provincia de Tarapacá, Iquique $2 / 12 / 1884$, sin fol.

4 Por ejemplo, la resolución tomada el 18 de junio de 1883 por el Jefe Político, Francisco Valdés Vergara, de caducar las patentes mineras que se amparaban en la ley peruana del 12 de enero de 1847 obligando a los empresarios del rubro a regirse por las normativas chilenas que contemplaban una contribución mensual de 30 pesos. En AIT, vol. 55, Contribución de minas, Iquique 18/6/1883, sin fol.

5 AIT, vol. 56, División del departamento de Pisagua, Santiago $17 / 11 / 1884$, sin fol.

6 AIT, vol. 68, Envío de datos a la Oficina Central de Estadísticas, Iquique 21/7/1884, sin fol.; AIT, vol. 56, División del departamento de Pisagua, Santiago 17/11/1884, sin fol.

7 El Ferrocarril, Aduana, Escuela Domingo Santa María, Huantajaya, Caleta Buena, Patillos, Pozo Almonte y La Noria

8 AIT, vol. 56, División del departamento de Tarapacá, Santiago 18/11/1884, sin fol.

9 AIT, vol. 110, División administrativa del departamento de Tarapacá, Iquique agosto 1887 , sin fol.

10 AIT, vol. 56, Realización del censo en el territorio de Tarapacá, Santiago 12/5/1884, sin fol.
11 AIT, vol. 291, Población del departamento de Tarapacá, Iquique abril 1885 , sin fol.

12 AIT, vol. 74, Datos poblacionales del departamento de Pisagua, Pisagua 19/11/1885, sin fol.

13 AIT, vol. 249, Población de la provincia de Tarapacá, Iquique junio 1892, sin fol.

14 AIT, vol. 242, Población del departamento de Pisagua, Pisagua 1/7/1892, sin fol.

15 Juan Guillermo Álvarez, Memoria Instrucción Primaria de Tarapacá 1918, Imprenta La Nacional, Iquique 1919, pp. 2-3. En ARTIT, vol. 6, Memorias Públicas 1918, Memoria Instrucción Primaria de la provincia de Tarapacá, Iquique $31 / 1 / 1919$, sin fol.

16 De hecho, en el Departamento de Pisagua el aparataje fiscal destinado a la zona andina (Registro Civil, Notaría, Posta de Correo y Telégrafos, etc.) se terminó habilitando en la localidad más cercana y con nexo vial regular a la pampa salitrera y a la costa: el pueblo de Tarapacá, quedando las restantes áreas rurales carentes de este tipo de servicios, lo que obligó regularmente a sus habitantes a tener que "bajar" para acceder a estas oficinas cuando lo requerían.

17 ARTIT, vol. 2, Subdelegaciones 1927-1928, Informe del Subdelegado de Camiña a los Inspectores de Distritos, Camiña 8/10/1927, sin fol. Lamentablemente no hemos podido ubicar este censo económico para verificar y analizar sus resultados. En consecuencia no tenemos certeza si se llevó a cabo tal cual como estaba previsto.

18 AIT, vol. 73, Denuncia por maltratos en el pueblo de Camiña dirigida al Intendente de Tarapacá, Camiña 14/7/1885, sin fol. Los firmantes de este reclamo fueron: Timoteo Zeballos, Braulio Aranívar, Seferino Luna, Luis León Meneses, Daniel Luna, Santiago Chambe. Juan L. Ossio, Félix Segundo Aranívar, León Ilaja, Eloy Rivera y Vera, Valentín Mamani, Gonzalo Aranívar, Gabino Platero, José Manuel Aranívar, Aurelio Aranívar, Eloy Luna, León Cayo, Bernardo Choque, Pedro Z. Vásquez, Martín Andía, Severo Choque, Juan Andía, Melchor Guaman, Pablo Ossio, M. Caques, Mariano Hidalgo, Manuel Pizarro, José 
L. Aranívar, Juan Pío Caques, Ronualdo Luna, Francisco Platero, Numa Loayza, José Rosa Chambe, Juan Castro, Tomás Lucrecio, Joaquín Ossio, Mariano Aranívar. A este listado hay que agregar dos nombres ilegibles.

19 AIT, vol. 150, Solicitud vecinos de Tarapacá para mantener a Subdelegado, Tarapacá 8/5/1889, sin fol. Entre los firmantes de esta petición se destacaron Miguel A. del Carpio, Griseldo Luza, Manuel Butron, Severino Terrazas, Mariano Sachura, Manuel Galeas, Apolonio Mollo, Mariano Carruncho, Martín Vernales, Valentín Cayo, etc.

20 AIT, vol. 197, Informe sobre las quejas contra el Inspector de Sotoca, Tarapacá 31/8/1893, sin fol.

21 AIT, vol. 197, Informe del Subdelegado de Tarapacá al Intendente de la provincia sobre inconvenientes fronterizos en Cariquima, Tarapacá 20/5/1895, sin fol.

22 AIT, vol. 197, Informe del Subdelegado de Tarapacá al Intendente de la provincia sobre inconvenientes fronterizos en Cariquima, Tarapacá 20/5/1895, sin fol.

23 AIT, vol. 67, Descripción de Tarapacá dirigida al Ministro del Interior, Iquique 5/6/1884, sin fol.

24 AIT, vol. 197, Informe del Subdelegado de Tarapacá referente a las dificultades para reclutar Jueces de Distrito, Tarapacá 30/8/1893, sin fol.

25 ARTIT, vol. 47, Subdelegaciones 1911, Informe sobre destitución del Inspector de Cariquima, Tarapacá 12/1/1911, $\sin$ fol. En el documento donde se sacó la referencia aparece textualmente como Esteban Challpa, sin embargo, es plausible que el mencionado Inspector reemplazante se haya llamado Esteban Challapa.

26 ARTIT, vol. 47, Subdelegaciones 1911, Quejas por falta de Juez de Subdelegación, Tarapacá 7/2/1911, sin fol.

27 ARTIT, vol. 1, Solicitudes 1917, Carta del vicario de Mamiña al Intendente de Tarapacá, Mamiña 16/3/1917, $\sin$ fol.

28 ARTIT, vol. 1, Copiador de Cartas 1908-1913, Oficio para traslado residencial de Subdelegado de Tarapacá, Iquique 17/12/1912, sin fol.

29 ARTIT, vol. 16, Subdelegaciones 1918, Informe del Inspector de Huaviña sobre el actuar del Juez de Distrito, Huaviña $5 / 5 / 1918$, sin fol.

30 ARTIT, vol. 16, Subdelegaciones 1918, Informe del Inspector de Huaviña sobre el actuar del Juez de Distrito, Huaviña $5 / 5 / 1918$, sin fol.
31 ARTIT, vol. 2, Subdelegaciones 1927-1928, Informe del Subdelegado de Camiña al Intendente de Tarapacá, Camiña 8/10/1927, sin fol.

32 AIT, vol. 197, Informe del Subdelegado de Tarapacá al Intendente de la provincia sobre inconvenientes fronterizos en Cariquima, Tarapacá 20/5/1895, sin fol.; AITRI, vol. 7 , Subdelegados 1910, Informes diversos sobre incidentes entre habitantes de Cariquima y residentes bolivianos de Llica, Tarapacá 8/8/1910, 18/1071910, 6/11/1910, sin fol.; ARTIT, vol. 28, Subdelegaciones 1921, Informe sobre los residentes peruanos del valle de Tarapacá, Tarapacá 28/9/1920, sin fol.

33 AIT, vol. 67, Descripción de Tarapacá dirigida al Ministro del Interior, Iquique 5/6/1884, sin fol.

34 AIT, vol. 67, Descripción de Tarapacá dirigida al Ministro del Interior, Iquique 5/6/1884, sin fol.

35 AIT, vol. 67, Descripción de Tarapacá dirigida al Ministro del Interior, Iquique 5/6/1884, sin fol.

36 AIT, vol. 68, Informe del Intendente de Tarapacá al Ministro de Hacienda sobre solicitud de Claudio Mackenna de agua y pastos de Lirima, Huasco y Caposa, Iquique junio 1884, $\sin$ fol.

37 AIT, vol. 68, Informe del Intendente de Tarapacá al Ministro de Hacienda sobre solicitud de Claudio Mackenna de agua y pastos de Lirima, Huasco y Caposa, Iquique junio 1884, $\sin$ fol.

38 AIT, vol. 68, Instrucción del Intendente de Tarapacá al Subdelegado de Pica, Iquique junio 1884, sin fol.

39 AMIOP, vol. 2119, Oficio del Director General de Obras Públicas al Ministro de Obras Públicas, Santiago 28/12/1918, sin fol.

40 ARTIT, vol. 28, Subdelegaciones 1921, Informe sobre los residentes peruanos del valle de Tarapacá, Tarapacá 28/9/1920, sin fol.

41 ARTIT, vol. 6, Oficios a los Ministerios 1930, Oficio del Intendente de Tarapacá al Ministro del Interior, Iquique $12 / 11 / 1920$, sin fol.

42 ARTIT, vol. 2, Subdelegados 1927-1928, Informe del Subdelegado de Tarapacá sobre venta ilegal de alcohol y actos anti-chilenos en las fiestas religiosas de su jurisdicción, Tarapacá 5/5/1927, sin fol. 
